\title{
A função social do jurista e a reforma do ensino do Direito
}

\author{
Prof. A. F. Cesarino Junior \\ (Catedrático de Legislação Social)
}

\section{Discurso do paraninfo da Turma de 1954 da Faculdade de Direito, da Universidade de São Paulo.}

Saio, por uns momentos, das profundezas do meu luto, para os esplendores desta solenidade, em virtude de um imperativo de conciência.

Em dezesseis anos de magistério universitário jamais me passou pela mente a possibilidade sequer, de vir um dia a ser paraninfo de uma turma desta Faculdade. Dedicado §o ensino, mais por vocação, que por profissão, sempre entendi ser meu dever ensinar e exigir, trabalhar e fazer trabalhar. Cônscio de que nem todos pensariam como eu, muitas vêzes vi interpretado como "neurose do trabalho", o que não passava de esfôrço no sentido de cumprir bem a minha missão de professor, ou traduzido por "sadismo nos exames", o que era apenas a vontade bem intencionada de estimular os jovens ao estudo honesto e eficiente. Certo, pelo ceticismo, que infelizmente o perpassar dos anos nos infunde, de que a intransigência no cumprimento do dever muitas vêzes nos afasta numerosas simpatias, já há muito me havia desencantado de que algum dia me pudesse caber a honra excelsa de ocupar esta tribuna, como paraninfo de uma Turma de Bachareis em Direito. 
É que, muito embora conhecesse as muitas e preciosas qualidades que exornam a maioria dos alunos desta Casa, nunca havia pensado suficientemente que na sua irrequietude havia também um profundo senso de responsabilidade e sob a sua aparente indiferença, uma extraordinária dose de generosidade.

Assim é que, abandonando velhas praxes, resolveram os bacharelandos de 1954, os componentes desta turma do IV Centenário de nossa querida São Paulo, colocar na lista dos Professôres, entre os quais iriam posteriormente escolher o seu paraninfo, exatamente aquêles de seus Mestres mais visados pela fama de rigorosos e exigentes. $\mathrm{E}$, dentre êles, escolheram, num primeiro escrutinio, um dos mais brilhantes, pela sua inteligência e pela sua cultura, não obstante a sua juventude, e dos mais estimados pela lhaneza do seu trato e pelos seus dotes de coração, a par de suas qualidades de Professor assíduo, operoso, eficiente e dedicado. Mas não o elegeram, estou certo, apenas por êsses títulos, suficientes por si sós para justificar-lhe a investidura: quizeram também dar ao eminente Professor Alfredo Buzaid, um lenitivo para a dôr que lhe trouxe a perda brutal e simultânea de dois entes queridos. Não pôde, porém, êsse nosso eminente Colega, forçado por escrúpulos cuja delicadeza todos compreendemos e admiramos, aceitar a dignificante incumbência, da qual se haveria, sem dúvida alguma, desempenhado com brilhantismo sem par.

Voltaram-se, então, os jovens diplomandos, levados pelo mesmo impulso de solidariedade humana, para a figura muito mais modesta de um seu velho Professor, a quem a fatalidade atingira com um golpe semelhante e lhe deferiram a honra que Alfredo Buzaid fôra impedido de aceitar.

Cumpre-me, assim, portanto, de vez que não se ouvirá, neste instante a voz do Prof. Alfredo Buzaid, agradecer duplamente êsse gesto esplêndido da mocidade acadêmica, 
em seu nome e no meu próprio, não precisando dizer-lhes quanto os nossos corações se sentiram sensibilizados e até certo ponto confortados com a gentileza recebida.

E, ficai certos, o abraço que, como padrinho, vos dou neste momento, é tão sincero como o que dei, como pai, há quatro anos, neste mesmo lugar, a um colega vosso que não mais existe.

De par com a minha gratidão, quero ao mesmo tempo exaltar devidamente êsse vosso gesto de solidariedade humana. Para mim, esta virtude, porisso mesmo que existe em tôdas as religiões, é a religião das religiões, é a minha religião.

Ao mesmo tempo, reconheço a responsabilidade da investidura que me destes. Esta é uma turma excepcional. Excepcional não apenas pela circunstância òbviamente fortuita de ser a turma do IV Centenário, mas pelo valor de seus componentes. Convivi convosco um ano apenas. Interessado que sou, porèm, pelas pessoas humanas de meus discípulos, bastante pude observar dos vossos esforços, muitos de vós alternando o estudo com o trabalho e o trabalho com o estudo, como principalmente êsses operosos e distintos alunos do Curso Noturno. Sois, ademais disto, excepcionais pelos alevantados ideais que revelastes acalentar e dos quais destes prova demonstrando compreender o anseio daquêles que lutam pela renovação dos métodos de ensino do Direito. Evidenciastes, assim, uma consonância perfeita com o espírito que anima a obra dos paulistas. Se São Paulo é a cidade que mais cresce no mundo, isto se deve ao fato de ser a cidade que mais trabalha no mundo. E ao mesmo tempo, a cidade que mais inova no mundo. $E$ isto pelo entendimento justo de que, embora devamos respeitar as nossas tradições, nos não devemos apegar a elas de maneira a permitir-lhes que nos entravem o progresso. Embora vos confesse que a minha pouca inteligência não me permite compreender as decantadas maravilhas da arte moderna, não posso desconhecer 
o fato de que São Paulo também se distingue no mundo com as suas famosas "Bienais". E não me ofende vêr a mais tradicional das nossas tradiçóes magnificamente representada no esplêndido monumento às Bandeiras, que guarda a entrada do Ibirapuera.

Vós, Bacharéis do IV Centenário, escolhendo para vosso paraninfo um lidador obscuro pela remodelação do ensino jurídico, mostrastes que, muito embora, como todos nós, respeitais as tradições desta Casa, sabeis também querer que a "Velha Academia" seja "sempre nova", em verdade e não apenas em evocações meramente poéticas.

$\mathrm{E}$ assim procedendo, me haveis do mesmo passo dado o têma para esta última palestra que, oficialmente, como Professor e alunos, ou melhormente, como padrinho e afilhados, realizamos neste instante.

Perdoe-nos o auditório o seu caráter talvez um pouco técnico. Bem sabemos que êle não se compõe apenas de bacharelandos de hoje, meus caros afilhados, de bacharelandos de manhã, meus prezados alunos, de bacharelandos de ontem, meus distintos Colegas. Compõe-se também de progenitores orgulhosos pela realização daquêles que são a sua própria realização; de irmãos satisfeitos pela vitória dos amigos que a natureza lhes deu; de noivas, promissoras esperanças de união da felicidade doméstica ao êxito profissional; para alguns, de filhos, que vêm na beca que lhes reveste o pai, o uniforme do futuro superhomem que, segundo esperam, êle vai ser.

Compreendo o seu júbilo e o seu justo orgulho e a êles me associo cordialmente. Sei, porém, que são todos paulistas, de nascimento ou de coração. E ser paulista significa amar o trabalho, desejar o progresso em todos os setores. É um êrro pensar-se que os paulistas se interessam sòmente pelo adiantamento econômico. As dezenas de Congressos científicos aqui realizados em comemoração ao IV Centenário demonstraram que nós somos igualmente um dos centros culturais mais avançados. E isso me leva 
a crer possa interessar-lhes meditar um pouco sôbre " $A$ Função Social do Jurista e a Reforma do Ensino do Direito".

Realmente, é preciso compreender de uma vez por tôdas a evolução que se operou nestes quatro séculos da vida paulista, vale dizer da vida brasileira.

As Faculdades de Direito, como sendo dos primeiros reais centros da atividade cultural do Brasil, representaram até há bem pouco tempo, o papel de verdadeiro Silogeu Brasileiro, de verdadeira síntese de nosso progresso espiritual, não apenas no terreno jurídico, como também nos campos literário e político. Daí o volume e a importância de sua tradição, que, aliados à versatilidade própria do talento de muitos dos seus filhos espirituais, fizeram das Faculdades de Direito verdadeiras Romas da nossa cultura e do nosso civismo.

Acontece, porém, que, da fundação dessas Academias até hoje, neste longo período de mais de um século, o nosso país muito tem evoluído, seguindo òbviamente a lei natural da evolução no sentido de uma crescente diferenciação, ou melhor, de uma cada vez maior especialização de atividades. Surgiram as Academias de Letras, fundaram-se Universidades, com as suas Faculdades de Filosofia, Ciências e Letras, criaram-se Escolas de Sociologia e Política, desenvolveram-se os partidos políticos, e assim, as Faculdades de Direito, embora continuem a ser dos mais importantes de nossos institutos culturais, deixaram de ter o caráter universal, díriamos até mesmo enciclopédico, decorrente da circunstância de serem quase a única reunião de homens preocupados com os problemas do espírito. Entretanto, o que perderam em extensão devem elas ganhar em profundidade.

Reduzidas, pelas circunstâncias acima apontadas a seu objetivo específico - a ensino do Direito, ao qual se deve acrescentar êste outro de que elas jamais abdicaram e jamais abdicarão - o culto do civismo, devem, a nosso 
vêr, as Faculdades de Direito adatar a sua própria organização de acôrdo com essas elevadas finalidades que lhes restam, procurando desempenhá-las da melhor forma possível. Para tanto não bastam a boa vontade e o esfôrço de seus membros, nunca desmentidos. $E$ mister fornecer-lhes instrumentos apropriados, através da modernização da sua própria estrutura, maxime da sua estrutura docente.

E, sobretudo, é preciso modificar o espírito com que, salvo raras exceções, se faz o ensino nas Faculdades de Direito.

Com efeito, não se pode desconhecer a importância da função do jurista na estrutura da sociedade contemporânea. A democracia, como forma mais elevada de concepção de vida, leva ao Estado de Direito. Leges ommes servi sumus, ut liberi esse possimus. Daí a necessidade de técnicos juristas para elaboração da lei, para sua execução de um modo geral, para sua aplicação aos casos particulares de sua violação e para o seu estudo e aperfeiçoamento. Se a democracia exige o Estado de Direito, se êste repousa na atuação dos juristas, a sua formação é assunto da maior importância. Daí a necessidade de ponderar sôbre o ensino do Direito. ê êle perfeito?

Ninguém negará que a organização atual do ensino do Direito é defeituosa. Ha ausência de assistentes. As catedras funcionam isoladas, o ensino é quase exclusivamente teórico, deixando em completa passividade os alunos. Há falta de contato entre êles e os professôres. A separação entre os corpos docente e discente é até mesmo, em alguns casos, já felizmente raros, representada materialmente pela altura da cátedra. $\mathrm{E}$, principalmente, prepondera ainda em alguns setores uma certa confusão entre o estudo do Direito e o estudo da literatura, uma profunda incompreensão pelo verdadeiro caráter técnico-cientifico da função do jurista.

Houve até quem afirmasse, desta mesma tribuna: "Nenhuma escola, ademais, pode formar advogados: as 
qualidades de advogados não se adquirem no aprendizado das universidades. Porque algumas são inatas, desenvolvendo-se nas refregas constantes da profissão. É um despautério exigir das Faculdades jurídicas que elas, sacrificando o seu fim cultural, se metamorfoseiem em escolas de rabulagem, se reduzam a cursos de redação, para ensinar a seus alunos a arte de escrever uma petição em português, já não dizemos de leì, que êsse anda hoje tão esquivo..". E eu vos pergunto, para que serve então a escola? E a mesma voz, hoje infelizmente apagada, responde: "A missão da Faculdade é muito mais alta: é a de fornecer os conhecimentos juridicos indispensáveis às profissões ou carreiras, a que o diploma dá direito, e que na de advogado se não enterreira, é a de formar a cultura jurídica do país".

Certo, reconhecemos que não é missão das Faculdades de Direito formar leguleios, mas insistimos: nem por ser superior, o ensino de Direito, no Curso de Bacharelado, deịa de ser um ensino profissional. E não podemos concordar com que se percam cinco anos da melhor época da vida, sem neles se aprender umra profissão. Se as qualidades do advogado são inatas, devem ser verificadas antes da admissão à Escola, mediante as competentes provas psicotécnicas. Se são adquiridas, devem ser ensinadas durante o Curso, usando-se para isto todos os meios lícitos. Sobretudo, o que se deve é estabelecer o contáto vivo do aluno com a realidade, em meio à qual êle vive a a que deve servir. De maneira alguma podemos concordar com a afirmação evidentemente paradoxal: "Se a realidade contraria as minhas teorias. tanto peor para a realidade!". E tão pouco com a definição de cultura, como sendo o que fica depois de esquecido tudo que se aprende. .

Não! A missão da Faculdade é a de fornecer os conhecimentos jurídicos indispensáveis às profissões ou car- 
reiras a que o diploma dá direito, mas êstes conhecimentos não são apenas teóricos, mas também práticos. O Direito, já o lembrava entre nós Pedro Lessa, não é apenas ciência, é também arte: "Investigar como se formou uma lei (na accepção technica, ou como expressão sinônima de norma), para bem lhe apreender o sentido, afim de applicá-la convenientemente, em tôda a sua pureza, de perfeita conformidade com o pensamento e a vontade do legislador, nunca se poderá dizer uma função da ciência, mas apenas um trabalho artístico". E como tal exige não somente leitura, ou audição de preleções, mas aprendizagem técnica, em que o discipulo deve, não apenas ver fazer, mas também fazer êle próprio sob o olhar vigilante do Mestre: "Cest en forgeant, qu'on devient forgeron". A teoria é indispensável, sem dúvida; ela é comparável aos olhos que guiam a mão do operário, mas não podemos esquecer que são as mãos que executam o trabalho. A repulsa pelo ensino prático, é, a meu vêr, ainda resquício dos preconceitos que sempre separaram as artes liberales das artes illiberales. Eles persistem ainda hoje e bem me lembro da onda que levantei na I Convenção Nacional do Partido Democrata Cristão, de que ao tempo era Presidente, quando propuz constasse de nosso programa o princípio de igualdade do valor do trabalho, aceito afinal, com a restrição de "igualdade moral do trabalho". É por isso que a reforma do ensino jurídico tem importância para o bom desempenho da função social do jurista, porque ela visa aproximar o estudo da realidade, o que vale dizer quase aproximar o estudante do operário, dando razão ao poeta que dizia:

"Em coisas de grandeza,

Colega, dá-me a mão,

$\mathrm{Tu}$ vales o que eu valho:

A tua, vem do rei,

E chama-se nobreza,

A minha, vem do povo,

E chama-se trabalho!". 
Não será sem dúvida descabido, neste momento, um olhar retrospectivo para a nossa vida nesta Escola, desde o exame vestibular até às últimas provas do $5^{\circ}$ ano. Esse olhar, para os jovens bacharelandos será repassado de saudades e, por isso mesmo cheio de poesia: para o velho Professor, porém, impregnado de espírito crítico e de preocupação pragmática. Não será fóra de propósito indagarmos nesta oportunidade se o ensino do Direito, tal como está organizado e é praticado, preenche as condições para uma bem feita formação dos juristas, sejam êles advogados, juizes, delegados, promotores ou professôres. E, não tenho dúvida, meus jovens Colegas, de que mau grado o vosso inato otimismo, a resposta será negativa.

Se não, vejamos. $O$ exame vestibular não apura qualidades para o exercício da profissão de jurista. Não há provas psicotécnicas reveladoras das inclinações e aptidões do candidato para a carreira jurídica.

Aqui vêm ter pessoas com vocação para a política, para os negócios, para a lavoura, para o teatro, para o cinema, para a literatura, para o rádio, etc., etc. Confesso que até hoje não compreendi porque procuram a $\mathrm{Fa}$ culdade de Direito e não a Escola de Sociologia e Política, a Faculdade de Ciências Econômicas e Administrativas, a Faculdade de Letras ou a Escola de Belas Artes.

As provas do pomposo "concurso de habilitação" versam sôbre Português, inclusive a malsinada literatura, Francês ou Inglês e Latim. Comecemos pelo latim. Por quê um exame puramente formal de latim, se $99,99 \%$ dos candidatos são incapazes de traduzir o texto sorteado na prova oral? Na verdade, a única utilidade do latim é enfeitar discursos com citações que bem poucos entendem. $\mathrm{E}$, principalmente, para que o exame de Latim, se o Direito Romano, cujo estudo se faria melhor no Curso de Doutorado que no de Bacharelado, consta, na sua maioria, pelo menos no "Corpus Juris Civilis", de textos facilimos, muito semelhantes ao português e ademais disto 
já traduzidos? Francês e Inglês são conhecimentos básicos em qualquer pessoa culta e é portanto simplesmente irrisório exigí-los em vestibulares às escolas superiores. 0 mesmo se diga do Português, que todo cidadão brasileiro ou português tem a obrigação de conhecer bem. Refletindo sobre a lista das materias do vestibular, chega-se à conclusão de que o legislador apenas pressupõe no candidato um conhecimentơ básico: o da alfabetização!

Enquanto isto, para candidatos que irão estudar problemas jurídicos, vale dizer, problemas sociais, e que irão receber o diploma de "Bacharel em Direito $e$ Ciências Sociais", não se exige nenhum conhecimento anterior de qualquer das ciências sociais! Dai a necessidade de se criar um Curso Preliminar ao Curso Jurídico, de pelo menos um ano, em que se estudem Sociologia, Politica, Economia, Finanças, Psicologia, Lógica, e as matérias propedêuticas: Estatística, Contabilidade e Organização do Trabalho Intelectual. Sem estas materias básicas o Curso Jurídico não tem infraestrutura, é uma construção de mera fachada, feita sem alicerces. Sôbre elas é que devará realmente versar o exame de admissão ao $1 .^{\circ}$ ano jurídico.

Quanto ao "curriculum", também deveria ser modificado, excluindo-se do Curso de Bacharelado, Economia Política, Ciência das Finanças, Direito Romano e Filosofia do Direito, as duas últimas sendo transferidas para o Curso de Doutorado e incluindo-se o Direito Econômico e o Direito Tributário. O Curso de Doutorado, por sua vez, seria um Curso de especialização, com seis séries: Teoria Geral do Direito, Direito Público, Direito Internacional, Direito Penal, Direito Privado e Direito EconômicoSocial.

Mas, o mais importante, é a reforma na organização e nos métodos de ensino.

Em primeiro lugar, os Professôres deveriam ser todos de tempo integral. E para que, com isto não se afastassem das cátedras justamente os mais capazes, que iriam aufe- 
rir maiores rendimentos em suas bancas de advocacia, todos os Professôres seriam ao mesmo tempo ou Desembargadores, ou Procuradores ou altos advogados do Estado, reunindo-se assim, à conveniência financeira, a de praticarem êles a profissão e de defenderem os interêsses públicos e não os particulares.

Por outro lado, teriam assistentes efetivos e extranumerários em número suficiente para que, não sòmente pudessem ser atendidos com a necessária amplitude os interêsses do ensino, mas também se transformasse a cátedra, no que ela deve realmente ser, isto é, um viveiro de futuros professôres.

Com isto e com a instituição de um ano letivo de dez mêses efetivos, com férias apenas em julho e em dezembro, seria possivel realizar um curso intensivo e, sobretudo, prático. Efetivamente, o ensino dos diversos ramos do Direito não deveria ser feito como é atualmente, quatro ou cinco dêles simultaneamente. $O$ certo seria fixar "têrmos" de dois, três, quatro mêses para cada um dêles, sendo que em cada têrmo haveria aulas teóricas, práticas, visitas, estágios e exercícios referentes ùnicamente a um determinado ramo do Direito. Concentrar-se-ia assim a atenção dos alunos sôbre êle, em lugar de dispersá-la, como atualmente, levando-se a concentração até ao ponto de se reunirem matérias afins, em verdadeiros Institutos de Direito Público, de Direito Privado, de Direito Econômico-Social, etc., que seriam não sòmente centros de aprendizado efetivo e eficiente, mas também ativos focos de pesquiza e de produção científica.

Os processos de exame deveriam também ser modificados, realizando-se sòmente "tests" escritos e provas práticas, apresentação de relatórios de visitas e estágios e redação de exercícios, através dos quais se pudesse realmente apurar o grau de preparo dos alunos. Seriam suprimidos os absurdos exames orais e com isto se daria um golpe de misericórdia na descabida crença de que todo individuo bem falante, prolixo, verboso, dará excelente 
advogado, donde outro absurdo, qual o de exigir-se no vestibular conhecimentos literários! Direito não é literatura, é ciência, e como tal deve ser estudado e ensinado. té um engano confundir o "orator" romano, com o advogado. Muito embora nosso processo se intitule "oral", na realidade êle é escrito e um gago pode ser melhor advogado do que um grande discursador. Basta que, conhecendo bem o vernáculo, e o ramo do Direito a que se dedica, conheça também lógica e, portanto, saiba argumentar. Insisto sempre em dizer que a definição de advogado de CELSO é incompleta: o advogado, não é apenas o vir probus, dicendi peritus, o homem honesto, perito na arte de falar. Ele deve ser o vir probus, dicendi "ac probandi" peritus, isto é, o homem honesto, perito na arte de falar (eu diria melhormente, de escrever) e, sobretudo, de provar. Com efeito, allegare et non probare, nihil est: o homem que alega, e não prova, não é honesto e, por isso mesmo, não é um advogado, mas um charlatão. E para provar, o advogado deve conhecer profundamente a sua ciência, teórica e pràticamente.

Devemos bater bastante nesta tecla da necessidade do ensino ser prático. Clama, ne cesses! Certo não se pretende que o ensino seja exclusivamente prático, pois isso seria formar leguleios, "rabulas" e não juristas. £́, porém, extremamente importante, tendo em vista ser o curso de bacharelado em Direito, muito embora superior, um curso profissional, uma vez ensinadas as noções teóricas indispensáveis, cujo desenvolvimento se fará no Curso de Doutorado, levar o aluno a compenetrar-se das realidades concernentes a sua futura profissão. E mister fazê-lo conhecer os instrumentos de que se vai utilizar (Códigos, repertórios de leis e de jurisprudência), levá-lo a visitar Tribunais e Repartições Públicas, fazê-lo presenciar atos forenses, redigir contratos, integrá-lo, enfim, no ambiente jurídico. É preciso que, do seu curso lhe resultem verdadeiras "vivencias" e não apenas vagas recordações de 
apostilas ou, no melhor, lembranças apagadas de nomes de autores e de livros, para cuja aquisição, em lugar de cinco anos de curso, bastariam cinco minutos de consulta a um catálogo.

Insistimos neste ponto básico: non multa, sed multum. Não encher o espírito do aluno de teorias contraditórias, ótimas para serem discutidas num curso monográfico de doutorado, mas fixar-lhe na mente as noções básicas, a terminologia técnica, o hábito dos atos fundamentais da profissão tais, como postular, provar, redigir contratos, para que ao terminar o curso esteja êle apto a realizar com segurança as atividades para as quais se supõe tenha sido preparado durante êle. Não é no bacharelado que o faremos doutor nem jurisconsulto: para isto há o doutorado e, sobretudo, o decurso do tempo. Já Ruy Barbosa prevenia, e com razão: "Onde os meninos campeiam de doutores, os doutores não passam de meninos".

Tôdas estas considerações me ocorrem, meus jovens Colegas, ao vêr-vos transpor neste instante, os umbrais desta Faculdade, para ingressar nas árduas lides que vos esperam. Sabeis que, pragmatista como sou até certo ponto (Nisi utile est quod facimus, stulta est gloria), no que me concerne, fiz o possível para preparar-vos de acôrdo com as idéias expostas, assim como o fizeram também outros Professôres. Mas, infelizmente, sabeis também e disto muitas vêzes vos ouvi amargas queixas, que a atual organização do ensino jurídico não permite sejam elas realizadas na sua plenitude, como é de desejar.

Sei, porém, e por experiência, quanto posso contar com a vossa generosidade. Muito embora para vós já não possam ser direta e imediatamente úteis as reformas propostas, sei que vos interessais por elas, pois, tanto como se fôssem para vós mesmos, as desejais para os vossos colegas de Escola, atuais e futuros.

Mais felizes que o plantador do carvalho ou da sequoia, vós vereis em breve o fruto dessas medidas, cuja efetiva- 
ção vos concito a auxiliar, repetindo com outros seus paladinos, o gesto de reconhecimento de sua necessidade que tivestes para comigo. Vossos filhos, que em grande número, serão por certo, em futuro próximo, alunos desta casa, hão de sair do Curso de bacharelado, senão advogàdos provectos, porque para tanto é mister a patina do tempo, profissionais seguros dos atos que deverão praticar no desempenho do mandato público ou particular que receberem; hão de encontrar no curso de doutorado um meio de aprofundarem, especializando-se, os seus conhecimentos técnicos e de fazerem progredir a ciência jurídica através das pesquizas que aí realizarem, e se reunirão em torno de seus Mestres, felizes êstes por verem que podem encaminhar os seus filhos espirituais para a senda do progresso cientifico.

Reconhecemos juntos as deficiências do curso jurídico e, portanto, do vosso curso. Tenho certeza, porém, de que, pelas esplêndidas qualidades que revelastes durante as aulas e pela honestidade de propósitos de que dão prova as vossas atitudes, sabereis suprí-las com relativa facilidade. Confio na vossa capacidade de esfôrço.

Vós sois fruto desta trepidante civilização paulista, e sabereis, portanto, fazendo das fraquezas fôrças, preencher as lacunas que encontrardes em vossa preparação para a vida profissional.

E com estas palavras paternais, de evocação de um futuro radioso para todos vós, na familia, na profissão, na vida pública, que eu desejo deixar-vos.

Deixar-vos, renovando-vos os meus agradecimentos pela honra insigne que me conferistes e pelo consôlo valioso que me proporcionastes; deixar-vos, assegurando-vos, que, seja onde fôr o lugar a que o futuro vos leve, lá estarão os olhos de meu coração, a acompanhar a vossa carreira e a regozijar-se com os vossos triunfos!

Aliás, em realidade, nem eu vos deixo, nem vós deixais esta Casa. Sei que a continuareis venerando, sei que 
continuareis estudantes de Direito e que a ela voltareis sempre, ou como Professôres, ou como alunos do Doutorado, ou como ex-alunos à sua Alma Mater!

Mas, Professor ou aluno, universitários ambos, trabalharemos unidos por um futuro melhor, para São Paulo, para o Brasil, para a Humanidade! 